Roberto Veraldi ${ }^{1}$

The "Gabriele d'Annunzio" University

Chieti and Pescara
UDK: $316.72(450)$

https://doi.org/10.18485/imp.2017.ch.22

\title{
SCHOOL, MULTICULTURALISM, SOCIALIZATION
}

\begin{abstract}
The common need to bring the claims of identity together, within the framework of the rules of liberal democracy, with a more or less long term project of real inclusion of minorities, assimilated through the socializing function of the school, may give rise to very different outcomes. From the legal point of view, two of the basic principles of democracy, i.e. the universality and equality of citizens, seem to be inevitably at odds with the demands for recognition based on identity with an increasing number of people raising their voices in the public debate. Therefore, interculturality is a method, not a goal, the same way in which migratory processes cannot be considered as a prerogative of a single discipline: nevertheless, an element inherent to sociology is a certain "imaginative" aspect that aims at deepening knowledge of socio-cultural reality.

Keywords: school, interculturality, socio-cultural reality.
\end{abstract}

Most sociological interpretations in the field of education can be divided into two groups, depending on whether they attach a positive or a negative function to education. The first group includes lists of sociological works and those based on the concept of human capital, according to which school education is (or more often may become, throughout the appropriate policies) a useful tool for social development and personal growth. The second, however, features interpretation schemes of a neo-Marxist approach in particular: the latter focus their criticism primarily on the characteristic of reproducing inequalities in the educational system, through students' interiorization of the existing order. In their original formulation, which can be traced to the works of Emil Durkheim and Karl Marx, both theories can no longer be considered valid; both because of the changes which have in the meantime taken place in society and the

roberto.veraldi@unich.it 
school system itself. Their major limitation seems to particularly relate to the underestimation of the complexity of school-individual-society relationship in favour of some kind of implicit sociological determinism. In both cases, the board will in fact only focus on certain elements (for example, personal preparedness as a lever for social mobility rather than social background as an obstacle to academic success), ignoring substantially their mutual interaction as well as the interaction with the environment and concrete persons. It is obviously impossible to deem correct the contrary approach either - to ignore the influence of these factors in favour of psychological reductionism that examines only individual cases, by exploring the uncertain, thus making impossible any kind of general sociological analysis.

This is obviously an intentional simplification: starting from a particular common basis, they have been developed further, and subsequent theories may also differ from one another greatly, while many of the inaccuracies and imprecisions of the initial formulations have been corrected and are increasingly incorporated into systems in more complex and flexible manners. Therefore, it is generally acknowledged that the educational system, at least in Western countries, carries out different functions, not only of transmitting knowledge, influenced in various ways in terms of its very structure by diverse interest groups in society, but not determined solely by them, and that the period spent in school has consequences on the mindset of the pupils, without which it would imply an absolute uniformity, the one adapted to a hypothetical standard seeing that it is always reinterpreted through the filter of specific circumstances and individual sensitivity. Therefore, it can be concluded that the school has an effective influence on the possibility of social integration of pupils, without offering any determinations, and should take action to ensure that the obvious differences (of origin, income, family situation, and so on), which cannot be eliminated by themselves, constitute nevertheless as little as possible objective obstacle to this goal. With that being said, this must have major consequences on the structuring of studies of educational institutions in different countries, or rather, their re-structuring in order to adapt them to the increasingly complex structure of the population. The common need to bring the claims of identity together, within the 
framework of the rules of liberal democracy, with a more or less long term project of real inclusion of minorities, assimilated through the socializing function of the school, may give rise to very different outcomes. From the legal point of view, two of the basic principles of democracy, i.e. the universality and equality of citizens, seem to be inevitably at odds with the demands for recognition based on identity with an increasing number of people raising their voices in the public debate.

The possible answers, grouped into four main sections, are ranging from an uncompromising defence of democratic-liberal values that stem from the French Revolution up to radical multiculturalism, through intercultural society and pluralist multiculturalism in all its possible nuances. These policy guidelines are then integrated into the existing school structures in various manners, carrying the characteristics of autonomy and centralization, flexibility or rigidity, skills and interests within themselves. Historically speaking, four ideal models that are typical of acculturation can be identified, corresponding to as many countries that were the first to implement them, always making sure, however, to remember that they are currently criticized and that they are a subject to revision in those same countries. These are:

- $\quad$ The American model of the melting pot (fusion of multiple cultures);

- The French model of assimilation (homologation to the culture of the host society);

- The German model of separation (like furrows between immigrants and the host society, which precludes cultural comparison);

- The Community model of integration (acceptance of immigrants in the host society as bearers of cultural particularities).

Nowadays, although in different ways and time intervals, most countries (at least at the European level) are going towards one model, definable full stakeholder, in which cultural diversity is enhanced to provide a source of mutual enrichment. By adding the irregular distribution of the immigrant presence on the territory of various States to this pic- 
ture, whereby there is an equally regular concentration of pupils of foreign origin in particular schools, we understand that it is not possible to give a general analysis of the situation if we are to avoid oversimplification.

Therefore, it is necessary to restrict the scope to at least one country; in this case this country will be Italy, where the education system is the subject of an extensive restructuring process, still in progress, in which two principles of reform operate simultaneously: the principle of subsidiarity with a broad administrative decentralization for providing both the teaching and organizational autonomy of educational institutions, and the principle of consistency regarding the European guidelines, which enables improvement and raises efficiency of the general level of training by increasing the participation rates in training activities with the perspective of lifelong learning.

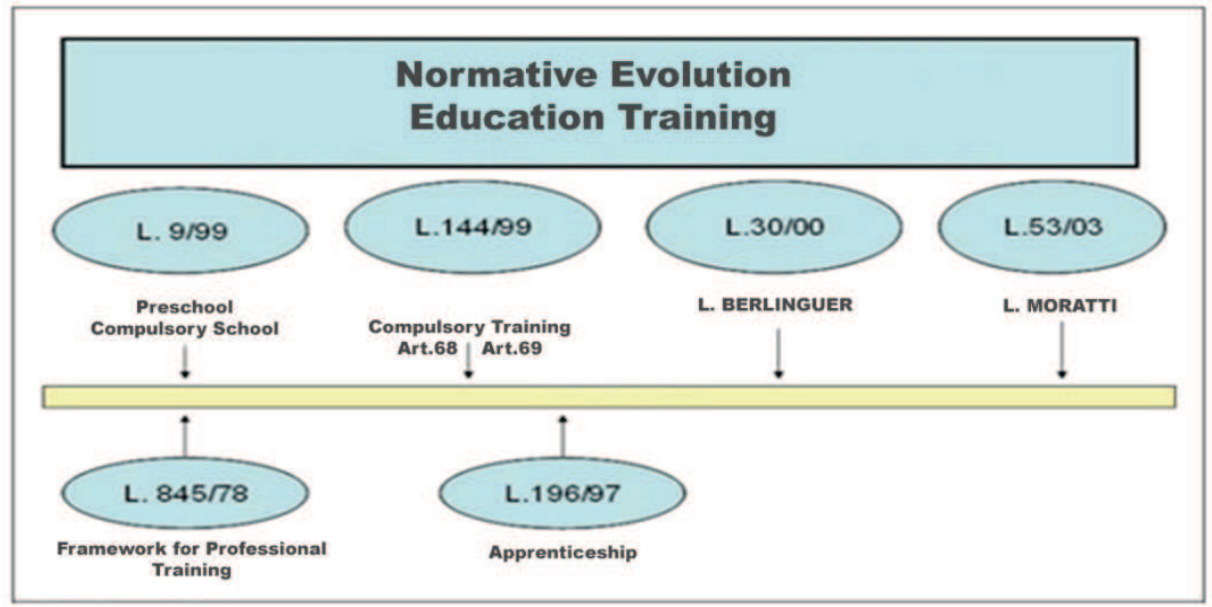




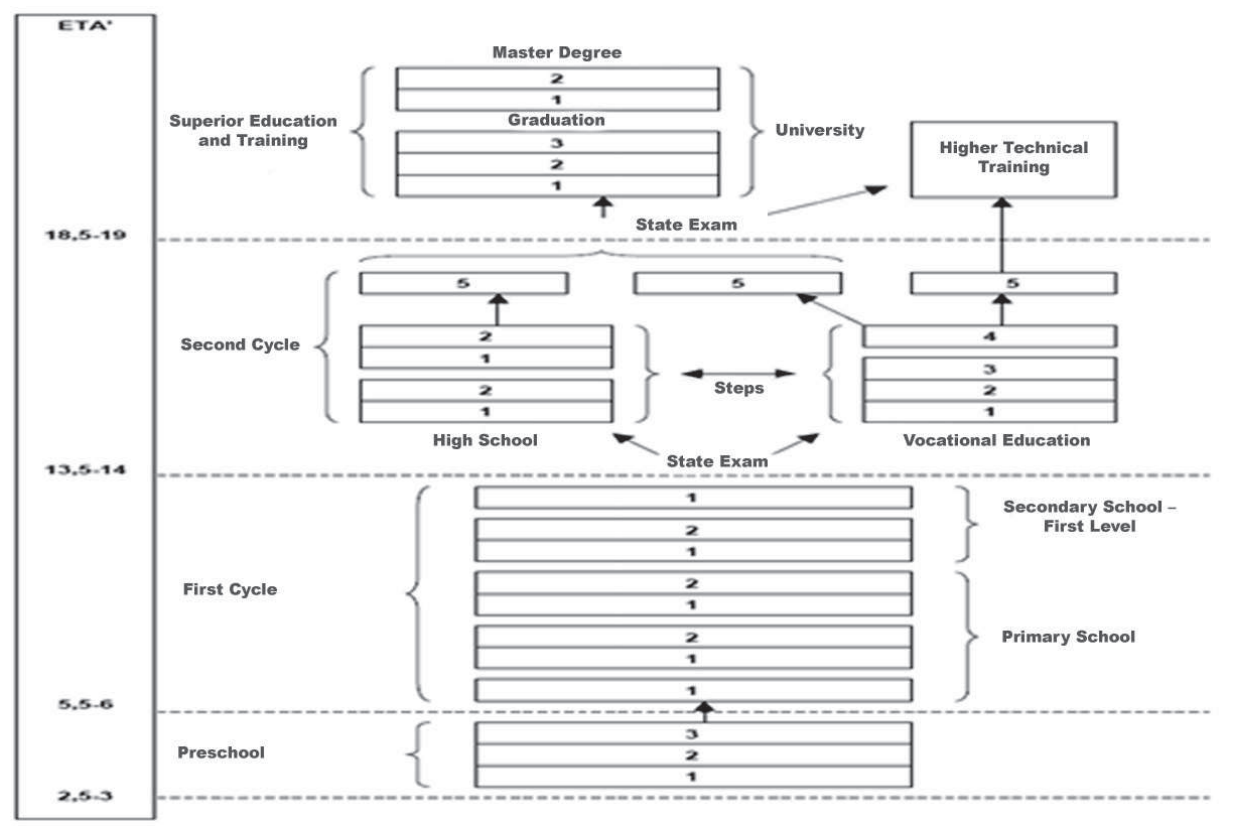

\section{The Dual Channel}

The Law 53/03 represents the reform that redefines the entire school system

There are two types of paths that children can do:

1) The System of the High Schools (8)

2 The System of Professional Education / Training

A "step" system allows you to switch from one channel to another 


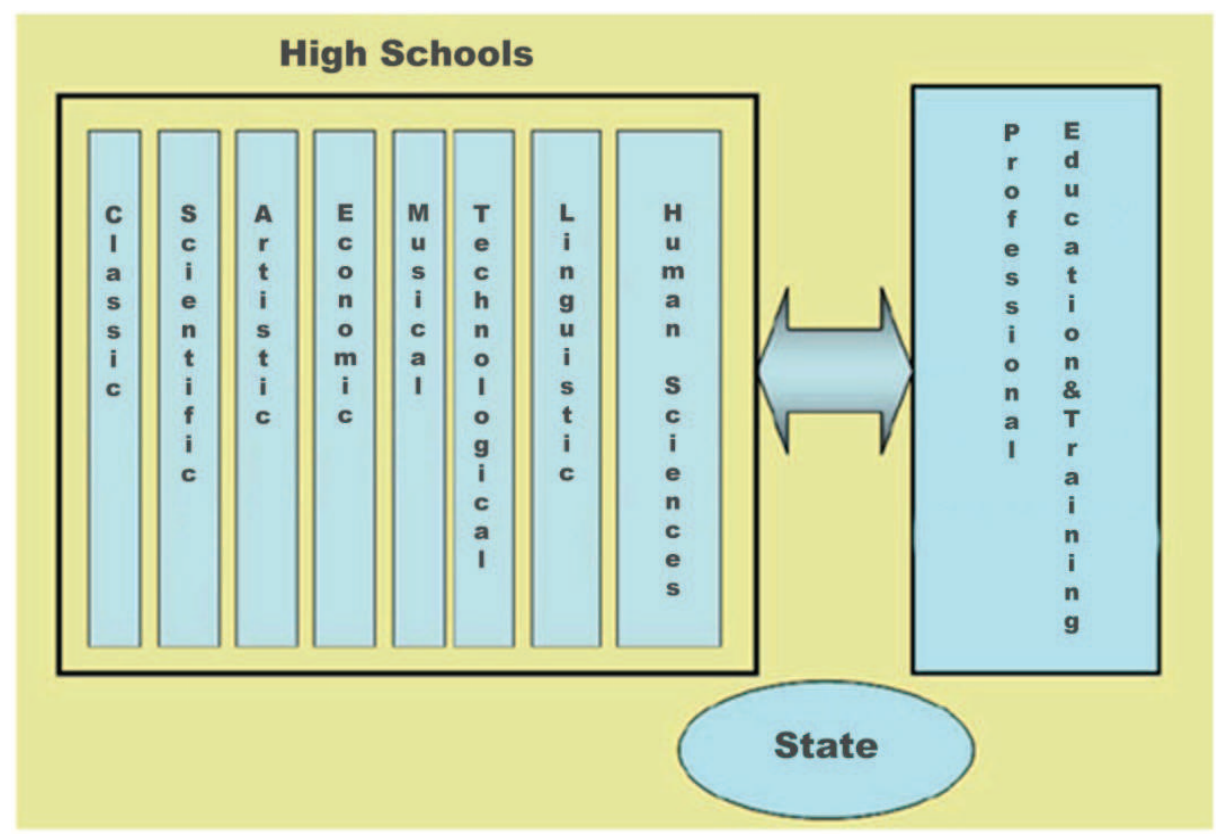

Source: TRANSALP - "Lavoro senza frontiere” ("Work Without Borders”)

When we speak of Europe, we may refer to two subjects: all Member States of the European Union and Nations that make up the geographical Europe. Although partially overlapping, the two realities are not completely interchangeable and the distinction is not entirely comprehensive, given the differences in terms of history, purpose and future prospects. A similar description can be made regarding school policies in general and, more particularly, those designed to encourage integration of pupils of foreign origin. Individual European States have school systems that are anything but uniform, considering that they resulted from the peculiar historical and political events of the country itself and due to which, in combination with the other factors of integration policies, the political system is well far away from an extremely varied framework.

The European Union, on the contrary, as a political "instrument" is a relatively compact front: under the Treaty of Amsterdam of May 1, 1999, the policy on immigration trends has become an area of shared responsibility and the European Commission itself has addressed this subject on several occasions, highlighting in particular the need for at least a cer- 
tain European dimension of education. The first legislative reference (the European Convention of 1977 on the status of migrant workers) dates back more than 30 years ago, since then lawmakers have moved altogether in the sense of a progressive enlargement of the scope of these forms of protection to include all children born in the host country, irrespective of their legal status. This is particularly evident from the Council of Europe recommendations on the subject (which is not mandatory for the member States) and it is hence conceivable that the process is far from over, especially in light of all the events on the migration phenomenon and policies that are shaking the European union to its foundations. By looking more closely at the concrete initiatives undertaken to implement what was previously indicated, even if solely at the level of intentions, we can distinguish two groups of instruments: those of promotion and those of control. The first group includes programs such as Socrates, Erasmus and Erasmus Plus, which, for example, provide for a period of studying abroad (not necessarily in a member state) and are intended to encourage the knowledge of languages and different cultures, in the framework of a cooperation contest between States aimed at bringing their respective educational systems closer. Although falling formally under the first of these initiatives, European network on training pertains to the second so-called euro group, which several years ago dealt specifically with the integration of pupils of foreign origin throughout the publication of monographs on the topic. This report highlights certain points that allow you to define a general framework for guidance.

Although these may no longer be reliable data, the percentage of immigrant population varies between 2.5 and $9.1 \%$ in most countries, but reaches its peak of $20-25 \%$ in smaller countries, such as Luxembourg and Liechtenstein.

The internal flow to the European Union is often overlooked, at least in common perception: even when limiting the possible origin to European countries, it is still the relative majority of the immigrant population in five countries, and represents at least a significant share in all the others.

The origin is still much diversified: although people of Russian origin are the most consistent in intra-European regard, the continents are represented in the groups of zones of origin, and in case when the main 
nation of origin is a third country, it is often connected to the final destination by historical ties (as in the case of Spain and Latin American Countries). The presence of such immigrants is most likely destined to grow quickly, in addition to admitting their relatives up until an unlikely complete closing of borders, due to the relatively young average age, high fertility rates and legal entry methods, such as family reunions.

In general, European law requires an equal treatment of children of citizens, legal immigrants and those who have applied for political asylum. Most countries have adopted legislations between 1998 and 2003. This equality of treatment involves access to educational services, which should be the same as for other students.

However, individual States may exercise this right in order to demonstrate an appropriate educational achievement or success in an examination, while, in some cases, the State gives the migrant the right to certain forms of aid, aimed at recovering the possible initial disadvantage.

By also limiting the examination solely to the cases of regular admission into the country, one can only imagine to what extent the actual recognized theoretical right does not always correspond to its effective application in practice.

The knowledge of the host country language is also the prerequisite to exercise fully the right to education. And, for this reason the language support measures are the most popular and the first to be implemented both inside and outside of school facilities. In general, we tend to favour the integration of foreign pupils into classes of similar age and combining the normal school hours with a model of "transition" support lasting not more than one year, to provide the minimum skills required. Some countries include, as an additional facilitation, a reduction of the number of pupils in heterogeneous classes, while in the Nordic countries (as well as in Estonia, Latvia and Cyprus) the option of bilingual teaching is offered. Only a few countries opt for a long period of separated teaching. Similarly to learning the language of the host country, this is the main tool to get in touch with the culture of that particular place, the same way the knowledge of the language of the country of origin often represents the main bridge to the maintenance of their roots.

Outside the context of linguistic measures, the situation becomes much more confusing: any supplementary measures, such as permissions 
for special religious holidays or no obligation to comply with the established dress code, are not typically encoded at the regulatory level, but are rather dependent on internal regulations of individual institutions. Therefore, one cannot draw a homogeneous picture, even when referring to individual countries, because some of them, such as France, Belgium, Netherlands, are comprehensively moving towards a forced homogenization, through the prohibition of carrying any kind of religious political symbols within the school.

Yet another problem is related to the communication between schools and families. One could say that it is essential to allow the individual to take advantage of all the educational opportunities available and to avoid being subjected to conflicting pressures in the two areas of reference. This is not a problem that only concerns immigrant families, however it is particularly felt by these due to the language barrier and any sort of resistance on the part of other family members to what can be seen as a vehicle of excessive westernization of the child. Most countries have also introduced various support measures to help immigrant families to enrol their children in schools and to follow their academic progress.

Finally, there is an intercultural aspect of education. An intercultural approach to all or certain subjects is generally expected in almost all countries, while in about one third of cases it is considered one of the integral parts of citizenship education and is therefore included in the civic, politics, sociology, philosophy and moral education.

Being closely related to the issue of integration, the intercultural approach is very often beyond strictly educational scope: in many of the countries the curricula offer is combined with extracurricular initiatives aimed at enhancing cultural diversity, such as the organization of meetings with representatives of immigrant communities. Nowadays, the intercultural dimension of teaching is included in teacher training provided in practically all countries, and, yet, even taking into account the generational change, it will take some time before we can realistically think that most teachers have received training on the subject.

Ultimately, the school and the entire educational system have an extremely important task in determining the possible future developments of the society in which we live, considering that the knowledge 
acquired in school should be later used in various ways depending on these developments.

The most important function of the school still relates to socializing individuals to the founding values of the society. Throughout this system, we continuously reposition ourselves in terms of inclusion and exclusion, with respect to the environment that surrounds us, organizations, regions, as well as to relational contexts.

Of course, given that the global society is multicultural by definition (i.e. see simultaneously present plurality of cultures, identity searches, persons who in turn interact, even in a conflicting manner, with their own as well as with other cultures), and that it is multicultural even within it, considering that the various multicultural groups that compose it are carriers of different value systems that coexist: in this perspective, multiculturalism seems similar to interculturality where it appears not as a reality that already exists in one or more areas, but as a way based on dialogue and mutual knowledge to bring about a new type of society.

In this type of society, the educational task will be to apply the specific character of mediation between different cultures; the one that is non reductive of different cultural contributions, but stimulating continuous comparison of different models.

This will involve not only the acceptance and respect of diversity, but also the recognition of its cultural identity in the daily search for dialogue, understanding and cooperation with a view to mutual enrichment.

In this context, intercultural pedagogy, which represents its implementation in education, will strive to produce an educational climate conducive to learning and exchange with other cultures, allowing a predisposition to reflection.

Therefore, interculturality is a method, not a goal, the same way in which migratory processes cannot be considered as a prerogative of a single discipline: nevertheless, an element inherent to sociology is a certain "imaginative" aspect that aims at deepening knowledge of socio-cultural reality. 


\title{
REFERENCE LIST
}

Ambrosini, Maurizio. Sociologia delle migrazioni. Bologna: Il Mulino, 2005. Stampa.

Benadusi, Luciano. Sociologie dell'educazione a confronto. Firenze: La Nuova Italia Editrice, 1993. Stampa.

Colombo, Maddalena. Relazioni interetniche fuori e dentro la scuola. Milano: Franco Angeli, 2004. Stampa.

Giddens, Anthony. Sociologia. Trad. di Massimo Baldini, Gaspare Nevola. Bologna: II Mulino, 1995. Stampa.

Melucci, Alberto. Culture in gioco. Differenze per convivere. Milano: Ledizioni, 2010. Stampa.

Portera, Agostino. Manuale di pedagogia interculturale. Milano: Hoepli, 2013. Stampa.

Pratola, V. (a cura di). Educazione, scuola e disadattamento: riflessioni e proposte. Scritti di Veraldi R. et al. Pescara: Libreria dell'università Editrice, 1998. Stampa.

Sciolla, Loredana. Sociologia dei processi culturali. Bologna: II Mulino, 2002. Stampa.

TRANSALP - Lavoro senza frontiere. "Il Sistema Scolastico in Italia". Servizi per I'Impiego, Lavoro, Istruzione e Formazione. 2006. Web. 25.01.2017.

Thuram, Lilian. Per l'uguaglianza. Come cambiare i nostri immaginari. Traduzione dal francese di Sara Prencipe. Torino: ADD Editore, 2014. Stampa.

\section{Roberto Veraldi}

\section{ESCUELA, MULTICULTURALISMO, SOCIALIZACIÓN}

\begin{abstract}
Resumen
La necesidad común de reunir las reivindicaciones de identidad, bajo las reglas de la democracia liberal, con un proyecto más o menos a largo plazo de la inclusión real de las minorías, en particular a través de la función socializadora de la escuela, puede conducir a resultados muy diferentes. Dos de los principios fundamentales de la democracia, a saber, la universalidad y la igualdad de los ciudadanos desde el punto
\end{abstract}


de vista jurídico, parecen estar inevitablemente en desacuerdo con las solicitudes de reconocimiento sobre la base de la identidad que un número creciente de voces alza en el debate público.

La interculturalidad, entonces, será un método, no un objetivo, tales como los procesos de migración no pueden considerarse una prerrogativa de una sola disciplina. La sociología es un recurso imprescindible en este proceso, que tiene el objetivo de profundizar el conocimiento de la realidad sociocultural.

Palabras clave: escuela, interculturalidad, realidad sociocultural. 